\title{
The Benefit of Acetyl-L-Carnitine in Chemotherapy Induced Peripheral Neuropathy: A Systematic Review
}

\author{
Rizaldy Pinzon ${ }^{1,2 *}$ and Fransiscus Buwana ${ }^{1}$ \\ ${ }^{1}$ Department of Medicine, Duta Wacana Christian University, Indonesia \\ ${ }^{2}$ Department of Neurology, Bethesda Hospital, Indonesia
}

*Corresponding author: Rizaldy Taslim Pinzon, Faculty of Medicine Duta Wacana Christian University and Neurology Departement, Bethesda Hospital, Indonesia. Dr. Wahidin Sudirohusodo No.5-25, Kotabaru, Yogyakarta, Indonesia.

\author{
Received Date: November 06, 2019
}

Published Date: November 18, 2019

\begin{abstract}
Chemotherapy induced peripheral neuropathy (CIPN) is the most common neurological syndrome secondary to antineoplastic therapy. The CIPN primarily affecting patients being treated with taxanes and platinum derivatives. The most common complain is sensory neuropathy. The available treatment for neuropathic pain are not come from chemotherapy induced peripheral neuropathy sub group population. The existing treatment is only symptom control and can not prevent further damage of the nerve. This study aimed to perform systematic review of the literature on the benefit of Acetyl L Carnitin (ALC) for chemotherapy induced peripheral neuropathy. The ALC is believed to increase the Nerve Growth Factor (NGF) that play important role in nerve health. Recent studies have shown that ALC is promising. The statement come from low quality evidences. Further studies with more valid approach are warranted.
\end{abstract}

Keywords: Chemotherapy induced peripheral neuropathy; ALC; Systematic review; RCT

\section{Introduction}

Peripheral neuropathy (PN) is the most common disorder of the peripheral nervous system in adults, and its prevalence increases with age. Estimating its prevalence in the general population is difficult because the documentation of this disease is often poor and insufficient. The available data often focus either on the prevalence in certain subgroups, for example patients with HIV, or cancer induced PN, or on neuropathic pain (NeP), which contributes to the variation [1]. In recent years, chemotherapy-induced neuropathies have also gained importance due to the increasing prevalence of cancer and the use of new chemotherapeutics and targeted agents like platinum derivatives, vinca alkaloids, taxanes, and antibody based drugs [2]. Several treatment options for PN are available, including pharmacological, non-pharmacological, and alternative options $[3,4]$. Patients suffering from severe and disabling symptoms (e.g. Neuropathic Pain) may require guideline treatments like pregabalin, duloxetine, or gabapentin initially until the symptoms are under control. These medications can symptomatically relieve the pain, but have significant side effects. These treatments are only symptoms control, and do not address the underlying cause $[4,5]$.

Experimental studies have shown the involvement of neurotrophic factors on CIPN pathophysiology [6]. Some studies showed that there is decrease in NGF (neural growth factor) with cisplatin, which would trigger CIPN. Several studies propose a protective role to BDNF (brain derived neurotrophic factor) in this syndrome [6,7]. Preliminary study showed that L-carnitine could have a neuroprotecting effect by different mechanisms, including increased NGF receptor expression [8]. Acetyl-L-carnitine (ALC), ie the acetyl ester of L-carnitine that plays an important role on mitochondrial energy homeostasis and detoxification and strengthening the actions of Nerve Growth Factors (NGF) and promoting peripheral nerve regeneration $[9,10]$. The important clinical question: "is there any benefit of ALC in patients with Chemotherapy Induced Peripheral Neuropathy ?". We perform systematic review to answer the question. We systematically find and appraise the available evidences that test the benefit of ALC in patients with chemotherapy induced peripheral neuropathy.

\section{Method}

We searched PubMed, Embase and the Cochrane Database of Systematic Reviews for relevant papers, considering publications issued before 2019. The following search terms were used: "acetylL-carnitine”, "neuropathic pain", "chemotherapy induced peripheral neuropathy" and "cancer related neuropathy". Full-length, RCT, 
open label trial, uncontrolled study, and original communications were included, limiting the search to English language publications. The review process was carried out by two reviewers using Jadad criteria. The following inclusion criteria were considered: trials including patients with a diagnosis of neuropathic pain related to cancer or cancer treatment related (chemotherapy), and a minimum sample size of 10 patients. The critical appraisal of the included studies are performed by using Jadad criteria [11]. The valid article should be randomized, controlled, blind assessment, and use intent to treat analysis. The scoring system are used to classify a study is valid or not. Score above 3 from possible 5 points are considered as valid study.

\section{Result}

We found three studies that evaluate the benefit of ALC for chemotherapy induced peripheral neuropathy. One trial with RCT method and 2 open label trial Table 1. describe the three studies. The first study is a large RCT. A prospective, double blind, Class II RCT study totaling 239 patients with chemotherapy induced

Table 1: The characteristics of the trials.

\begin{tabular}{|c|c|c|c|c|c|c|}
\hline Author (year) & Study type & $\begin{array}{c}\text { Follow up } \\
\text { duration }\end{array}$ & Subjects & $\begin{array}{l}\text { ALC daily } \\
\text { dose (mg) }\end{array}$ & Outcome Measure & Findings \\
\hline Sun et al. [12] & $\begin{array}{l}\text { Randomized } \\
\text { Controlled Trial }\end{array}$ & 2 months & 239 & 3000 & $\begin{array}{l}\text { Peripheral neuropathy } \\
\text { grade (NCI-CTC), NCS }\end{array}$ & $\begin{array}{c}\text { Reduced neurotoxicity: } 50.5 \% \text { of } \\
\text { patients NCV improvement: } 60,7 \% \\
\text { of patients }\end{array}$ \\
\hline Maestri et al, [13] & $\begin{array}{l}\text { Open label- } \\
\text { uncontrolled study }\end{array}$ & 0,25 month & 27 & 1000 & $\begin{array}{l}\text { Peripheral neuropathy } \\
\text { grade (WHO) }\end{array}$ & $\begin{array}{l}\text { At Least one WHO grade } \\
\text { improvement in } 73 \% \text { of patients }\end{array}$ \\
\hline Bianchi et al, [14] & $\begin{array}{c}\text { Open label- } \\
\text { uncontrolled study }\end{array}$ & 2 months & 25 & 3000 & Total neuropathy score & TNS improvement: $92 \%$ of patients \\
\hline
\end{tabular}

\section{Discussion}

Chemotherapy induced peripheral neuropathy (CIPN), often described as numbness, tingling, and neuropathic (burning, freezing, zapping, or shock like) pain in the hands and feet, is experienced by $20 \%$ to $85 \%$ of individuals who receive neurotoxic chemotherapy [15]. Common preclinical manifestations of CIPN, primarily a sensori motor axonal neuropathy are loss of vibration and temperature sensation, proprioception, and deep tendon weakness. However, autonomic symptoms such asorthostatic hypotension, loss of bladder control, constipation, hearingloss, and with daily activities (DA), functionality and behavior of cancer patients [18]. Verbalization of frustration feelings is common as a consequence of social role impairment, of distress due to functional skills changes, in addition to dismay and loss of objectives due to the need to give up some activities [19]. A cross sectional study has evaluated 706 patients with regard to the influence of CIPN in the development of mental and sleep disorders after the fourth week of potentially neurotoxic anticancer treatment. The worst CIPN severity, the highest the frequency of anxiety, depression and sleep disorders, which were worsened by neuropathic pain [19]. According to preclinical and clinical studies, ALC can be considered reflexes. Individuals may also report difficulty with balance, impaired fine and gross motor skills, and muscle cramps and difficulty obtaining an erection have also been reported [16,17]. CIPN has significant impact on quality of life, directly interfering peripheral neuropathy tested the effect of oral administration of ALC 3 g/day [12]. This study use National Cancer Institute Common Toxicity Criteria for primary end point. The subjects conditions were assessed at week 4, 8 and 12 after the baseline measurement. At week 8, 51.6\% patients treated with ALC met the primary end point, compared with $23.1 \%$ of patients in the placebo group. Secondary endpoints, such as sural nerve conduction velocity and in patients treated with ALC, compared to the placebo group. No significant difference in the incidence of adverse events between the two groups was observed. Two open label studies tested the effect of ALC in patients with neuropathy induced by paclitaxel and cisplatin [13,14]. Maestri, et al (2015) studied the effect of ALC $1 \mathrm{~g} /$ day i.v. infusion over $1-2 \mathrm{~h}$ for at least 10 days in 27 patients. The study showed that the peripheral neuropathy improved in $73 \%$ of them. Bianchi, et al studied oral ALC (1 g t.i.d.) for 8 weeks in 25 patients. The total neuropathy score, including neurophysiological measures, improved in $92 \%$ of them [14] (Table 1). the Karnofsky physical score showed also a significant improvement

both an etiological and symptomatic treatment in patients with peripheral neuropathy with a good safety profile. ALC operates via several mechanisms, inducing regeneration of injured nerve fibers, reducing oxidative stress, promoting DNA synthesis in mitochondria, and increasing NGF concentrations in neurons, thus promoting neurite extension [20,21]. Noteworthy, the analgesic effect of ALC exceeds by several days or weeks the end of treatment, in models of chronic inflammatory and neuropathic pain. This enforces the role of ALC as an analgesic drug and supports the role of the epigenetic mechanisms in the treatment of chronic pain [22]. This review has some limitations. This review found some heterogeneity among the study. The review only include papers that published in English. Future trials in patients with painful peripheral neuropathy of different etiology are needed.

\section{Conclusion}

Chemotherapy induced peripheral neuropathy (CIPN) is a frequent problem negatively interfering with anticancer therapy. Different drugs are associated to variable risk levels, which shows CIPN neurobiological complexity. Acetyl-L-carnitine (ALC) proved to be efficacy and safety for reducing chemotherapy induced peripheral neuropathy toxicity and its associated symptoms.

\section{Acknowledgement}

\section{None}




\section{Conflict of Interest}

No conflict of interest.

\section{References}

1. Hanewinckel R, M Van Oijen, MA Ikram, PA Van Doorn (2016) The epidemiology and risk factors of chronic polyneuropathy. Eur J Epidemiol 31: 5-20.

2. Callaghan BC, RS Price, EL Feldman (2015) Distal Symmetric Polyneuropathy: A Review. JAMA 314(20): 2172-2181.

3. Head KA (2006) Peripheral neuropathy: pathogenic mechanisms and alternative therapies. Altern Med Rev 11(4): 294-329.

4. Finnerup NB, N Attal, S Haroutounian, E Mc Nicol, R Baron, et al. (2015) Pharmacotherapy for neuropathic pain in adults: a systematic review and meta-analysis. Lancet Neurol: 14(2): 162-173.

5. Elmofty DH, M Anitescu, A Buvanendran (2013) Best practices in the treatment of neuropathic pain. Pain Manag 3(6): 475-483.

6. Aloe L, Manni L, Properzi F, De Santis S, Fiore M (2000) Evidence that nerve growth factor promotes the recovery of peripheral neuropathy induced in mice by cisplatin: behavioral, structural and biochemical analysis. Auton Neurosci 86(1-2): 84-93.

7. Cavaletti G, Marmiroli P (2006) The role of growth factors in the prevention and treatment of chemotherapy-induced peripheral neurotoxicity. Curr Drug Saf 1(1): 35-42.

8. Engle DB, Belisle JA, Gubbels JA, Petrie SE, Hutson PR, et al. (2009) Effect of acetyl-l-carnitine on ovarian cancer cells' proliferation, nerve growth factor receptor (Trk-A and p75) expression, and the cytotoxic potential of paclitaxel and carboplatin. Gynecol Oncol 112(3): 631-636.

9. Hart AM, Wiberg M, Terenghi G (2002) Pharmacological enhancement of peripheral nerve regeneration in the rat by systemic acetyl-L carnitine treatment. Neurosci Lett 334(3): 181-185.

10. Virmani MA, Biselli R, Spadoni A, Rossi S, Corsico N, etal. (1995) Protective actions of L-carnitine and acetyl-L-carnitine on the neurotoxicity evoked by mito- chondrial uncoupling or inhibitors. Pharmacol Res 32(6): 383389.

11. Jadad AR, Moore RA, Carroll D, Jenkinson C, Reynolds DJM, et al. (1996) Assessing the quality of reports of randomized clinical trials: Is blinding necessary? Controlled Clinical Trials 17(1): 1-12.
12. Sun Y, Shu Y, Liu B, Liu P, Wu C, et al. (2016) A prospective study to evaluate the efficacy and safety of oral acetyl-L-carnitine for the treatment of chemotherapy-induced peripheral neuropathy. Exp Ther Med 12(6): 4017-4024.

13. Maestri A, De Pasquale Ceratti A, Cundari S, Zanna C, Cortesi E, et al. (2005) A pilot study on the effect of acetyl-L-carnitine in paclitaxel- and cisplatin-induced peripheral neuropathy. Tumori 91(2): 135-138.

14. Bianchi G, Vitali G, Caraceni A, Ravaglia S, Capri G, et al. (2005) Symptomatic and neurophysiological responses of paclitaxel- or cisplatin-induced neuropathy to oral acetyl-L-carnitine. Eur J Cancer 41(12): 1746-1750.

15. Wang X, Shi Q, Dougherty P, Eng C, Mendoza TR, et al. (2016) Prechemotherapy Touch Sensation Deficits Predict Oxaliplatin-Induced Neuropathy in Patients with Colorectal Cancer. Oncology 90(3): 127135.

16. Cavaletti G, Jakubowiak AJ (2010) Peripheral neuropathy during bortezomib treatment of multiple myeloma: a review of recent studies. Leuk lymphoma 51(7): 1178-1187.

17. Argyriou AA, Cavaletti G, Bruna J, Kyritsis AP, Kalofonos HP (2014) Bortezomib-induced peripheral neurotoxicity: an update. Arch Toxicol 88(9): 1669-1679.

18. Speck RM, De Michele A, Farrar JT, Hennessy S, Mao JJ, et al. (2012) Scope of symptoms and self-management strategies for chemotherapyinduced peripheral neuropathy in breast cancer patients. Support Care Cancer 20(10): 2433-2439.

19. Hong JS, Tian J, Wu LH (2014) The influence of chemotherapy-induced neurotoxicity on psychological distress and sleep disturbance in cancer patients. Curr Oncol 21(4): 174-180.

20. Manfridi A, Forloni GL, Arrigoni Martelli E, Mancia M (1992) Culture of dorsal root ganglion neurons from aged rats: effects of acetyl-L carnitine and NGF. Int J Dev Neurosci 10(4): 321-329.

21. Hart AM, Wiberg M, Terenghi G (2002) Pharmacological enhancement of peripheral nerve regeneration in the rat by systemic acetyl-L carnitine treatment. Neurosci Lett 334(3): 181-185.

22. Di Cesare Mannelli L, Ghelardini C, Calvani M, Nicolai R, Mosconi L, et al. (2009) Neuroprotective effects of acetyl-L-carnitine on neuropathic painand apoptosis: a role for the nicotinic receptor. J Neurosci Res 87(1): 200-207. 